\title{
$\mathbb{E} \mathbb{N} \mathbb{R} \mathbb{A} \quad C O M P E T I C ̧ \widetilde{A} O \mathbb{E} A$ COOPERAĞ̃O: VALORES E ATITUDES

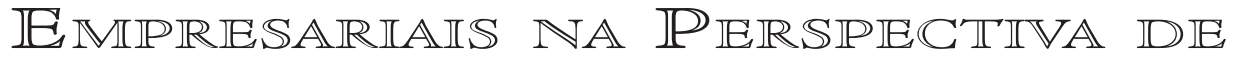 UMAA ATUAÇ̃̃O SISTÊMIICA ${ }^{1}$
}

\author{
Amilcar Baiardi* \\ Ruthy Nadia Laniado**
}

RESUMIO

presente trabalho discute o dilema entre competição e cooperação para as elites empresariais, focalizando um estudo sobre o empresariado baiano. Do ponto de vista analítico, aborda o entendimento sobre iniciativa, relações de poder, sistemas decisórios e valores éticos e sociais nos negócios. Debates atuais evidenciam que os empresários perseguem seus objetivos num universo marcado pela racionalidade e pelos ordenamentos formais - relacionando sua herança cultural com os novos valores de ação econômica voltados para a reestruturação organizacional do trabalho e da produção - defrontando-se com uma tensão contínua entre competição e cooperação, a qual se projeta nas suas redes de organização formal e informal. Tomando-se o empresariado baiano como estudo de caso, este trabalho discute alguns dos aspectos de como este dilema tem sido encaminhado, gerando sinergias em sociedades que se caracterizam por um tipo de dotação de capital social e por um engajamento cívico da elite empresarial diferenciados.

$\mathbb{A B S T R A C T}$

his paper discusses the dilemma between competition and co-operation among entrepreneurial elite, focusing on the study of entrepreneurs in Bahia. Analytically, it approaches the understanding of issues such as initiative, power relations, decision-making systems and ethical and social values in business. Contemporary debates flesh out that despite the entrepreneurs pursue their aims in a world marked by a rationality and a formal order - articulating their cultural heritage with the new values of economic action that involves restructuring labour and production organisation - they are faced with a continuum tension between competition and co-operation. This affects the formal and informal networks related to business organisation. This paper approaches some of the issues involved in this dilemma, according to a case study carried out with entrepreneurs in Bahia, by identifying guidelines related to the modes of producing synergism in societies, characterised by differentiated types of social capital and of civic engagement, among the entrepreneurial elite.

\footnotetext{
${ }_{1}$ Pesquisa realizada com o apoio do CNPq e dos bolsistas: N.R. Ramos, P.L.Santos, D. L. Salvador, P. B. Heine, B. S. Simas e C. D. Ribeiro.

* Professor do Núcleo de Pós-Graduação em Administração, NPGA, da Universidade Federal da Bahia e pesquisador do CNPq.

** Professora do Departamento de Sociologia, do Núcleo de Pós-Graduação em Administração, NPGA, da Universidade Federal da Bahia e pesquisadora do CNPq.
} 
ação empresarial voltada para criação e aprimoramento de condições sistêmicas pode resultar em uma maior eficiência da economia como um todo, inclusive no que respeita à maior coesão e menor exclusão social, funda mentais ao desenvolvimento sustentável (Coutinho \& Ferraz, 1994). Considera-se que a ação desses agentes fora dos limites da empresa revelaria um grau maior de modernidade da categoria, na medida em que os valores que a sustentam são aqueles que privilegiam a comunidade empresarial como um todo, independentemente de seus membros relacionarem-se entre si de forma competitiva ou de forma complementar. Dizendo de outro modo, a propensão a cooperar no âmbito empresarial sugere que a empresa ou a firma, sem renunciar à competição no mercado, entenda que a cooperação pode levar a que todo o tecido produtivo se torne mais competitivo. É a busca do que se chama qualidade integral, integralidade esta que se refere a uma comunidade industrial formada de muitas firmas, com alguma forma de conexão horizontal e/ou vertical. Esta qualidade tem sido obtida em regiões nas quais se concentram várias firmas concorrentes e, ao mesmo tempo, complementares, e que tenham um interesse de vender uma marca regional de um conjunto de empresas (Cianferoni, 1993).

Estudos recentes sobre as características regionais da Itália moderna sugerem a existência de um forte vínculo entre civismo e economia. Uma forma privilegiada desse vínculo manifestar-se é ao nível "microeconômico". Neste, um conjunto de firmas fisicamente próximas uma das outras, estabelecem conexões com vistas à cooperação (a) na dimensão operacional produtiva, que seriam as convencionais integrações vertical ou horizontal, e (b) na dimensão local, que seria uma inserção em uma mesma fração territorial - um mesmo município ou um grupo de municípios vizinhos -, com uma mesma identidade cultural.

Analisando exemplos de uma economia regional de pequena escala, mas altamente produtiva e tecnologicamente avançada como as do centro-norte da Itália, Piore \& Sabel (1983) classificaram as empresas ali presentes como detentoras de uma estrutura de especialização flexível, de tipo artesanal. Empresas como as têxteis e de alta costura dos arredores de Prato, as mini metalúrgicas de Brescia, as fábricas de motonetas de Bolonha, os fabricantes de ladrilhos de Sassuolo, etc., apresentavam como uma das suas principais características uma combinação, aparentemente paradoxal e contraditória, de concorrência com cooperação. As mesmas competiam acirradamente no campo da eficiência e da inovação em produtos, mas cooperavam nos serviços administrativos, na aquisição de matérias-primas e no financiamento da pesquisa e desenvolvimento de processos e produtos. Era comum encontrar empresas que combinassem uma alta integração vertical (cadeia produtiva de bens na qual o produto de uma indústria é insumo de outra) com uma alta integração horizontal (cadeia produtiva na qual várias indústrias participam de um produto final com produtos intermediários). Um exemplo conspícuo dessa coexistência da cooperação com a competição era a subcontratação, para trabalho extra, de concorrentes que estivessem, temporariamente, com capacidade ociosa.

Neste ambiente, ou entorno empresarial, associações industriais ali localizadas prestam assistência administrativa e até mesmo financeira, enquanto os governos locais propiciam a infra-estrutura e os serviços sociais indispensáveis, como treinamento profissional, informação sobre mercados de exportação, tendência mundial da moda, etc. Os autores concluem que a coesão da indústria repousa sobre um senso comunitário mais fundamental, do qual as várias formas institucionais de cooperação são antes o resultado do que a causa.

Cianferoni (1993), seguindo a mesma linha de análise de Putnam (1994) sobre a Itália, chama a atenção para o fato de que, além da combinação aparentemente contraditória da competição com a cooperação, as pequenas e médias 
empresas tecnologicamente avançadas da metade norte da Itália, sobretudo as da Toscana, constroem um pacto com vistas a obterem o nível de qualidade integral, que tem escala de rede e envolve cadeias produtivas. Este esforço de diferenciação frente ao consumidor seja ele nacional ou internacional, não é individual, não é de firmas isoladas, como o que ficou conhecido como a panacéia japonesa da qualidade total. Além da sinergia e dos conflitos, o que estas empresas buscam coletivamente é vender, realizar o marketing da região como uma totalidade e associar a seus produtos o selo DOC, denominação de origem controlada, e DOCG, denominação de origem controlada e garantida.

Em todo esse processo fica evidente a presença no seio da população de algumas instituições valorizadoras da confiança, da ajuda mútua e da solidariedade. A importância das instituições no esforço de busca de competitividade sistêmica não pode, em nenhum momento, ser negligenciada. No caso específico, as mesmas estariam concorrendo para a redução do que Williamson (1985) classifica como custos de transação, aqueles decorrentes de fiscalizar e fazer cumprir os acordos na gestão econômica das empresas. Um ambiente institucional baseado em regras de participação comunitária e calcado na cooperação e confiança minimizaria tais custos.

Sobre o papel das instituições no desenvolvimento econômico, que na busca da competitividade sistêmica têm um peso inequívoco, convém que se informe que tanto Williamson como Putnam são tributários, devedores mesmo, do pioneirismo de North (1990, 1991 e 1993) em abordar esta temática. A partir dos anos setenta, em seus estudos sobre história econômica, Douglass North vem chamando a atenção para o fato de que as instituições são invenções humanas, reguladoras de comportamentos individuais e sociais e cujo aperfeiçoamento constante é resultado de um bom funcionamento anterior, em todos os campos e com destaque para a vida econômica. Levando em conta esta abordagem para analisar o ocaso da Itália, Putnam (1994) sugere uma explicação de como e porque se constroem as instituições formais, aquelas que impulsionam a superação dos problemas da ação coletiva.

A análise precedente recomenda repensar-se a questão da competitividade além das tradicionais variáveis econômicas, como tamanho da firma, entre outras. Ao fazê-lo, deve-se priorizar a dimensão da cooperação na perspectiva da incorporação do progresso técnico, base importante dos ganhos de produtividade. A competitividade, que tem uma gama bastante ampla de variáveis como determinantes, é extremamente dependente de um sistema de inovações. Este, por sua vez, para se constituir requer, cada vez mais, trocas organizadas em redes, envolvendo o setor público e o setor privado e situando a cooperação como elemento fundamental. Em termos de política industrial, inclusive para a pequena e média empresa e para o desenvolvimento local, há a necessidade de se buscar uma nova noção de competitividade, inequivocamente vinculada à de cooperação entre atores dentro do tecido produtivo.

A cooperação entre empresas com grau variável de competição entre si não se dá sempre em um mesmo nível. Existem empresas que já se encontram maduras para a cooperação com vistas à qualidade integral e empresas que dependeriam de algum acicate, de intervenções voltadas para uma animação na linha de uma participação conjunta na esfera produtiva. As intervenções poderiam ser do tipo processo educativo, que poderiam deflagrar uma verdadeira revolução cultural baseada em experiências afirmativas de ação coletiva, visando melhorar as condições em que se observam as transações ${ }^{2}$. Estas últimas, tratadas como relações contratuais formais e informais, baseiam-se em relacionamentos de confiança e em outras formas de atuação, que não passam exclusivamente pela via do mercado, mas que são, comumente, ligadas à esfera da organização institucional. As transações, em condi-

2 O conceito de transações aqui utilizado é aquele que se refere aos domínios (Farina e Zylberstajn, 199.) e que foi inicialmente proposto por North (1990 e 1993) e Williamson (1993). 
ções de baixa cooperação e confiança, têm, em geral, custos elevados (Farina e Zylberstajn, 199.) Em última análise, há uma convergência ao se afirmar que a performance econômica é sensivelmente melhor quando os custos das transações são baixos ou ausentes (North,1990 e 1993; Williamson, 1993).

Além do empenho de redução dos custos transacionais, é indispensável que as intervenções voltadas para os empresários, agentes econômicos centrais, se inspirem em algumas experiências que têm dado certo no plano internacional, nas quais, pequenos, médios e até mesmo grandes empresários, participam do comércio internacional em condições vantajosas. Estes agentes podem constituir alianças exitosas através de consórcios que nada mais são que organizações cooperativas, sem os entraves e os riscos da cooperativa como uma instituição formalizada. O consórcio permite uma maior flexibilização tanto da participação dos associados como das operações de produção. Muitos deles não têm sequer regras escritas, por isso dependem de uma acentuada confiança e cooperação na sua constituição. Em decorrência, podem desenvolver uma significativa capacidade de fortalecer a coesão social.

Um outro elemento fundamental do modelo italiano é a integração em redes, formadas a partir de complementaridades necessárias, identificadas ao longo de cadeias produtivas ou a partir de objetivos comuns, como a organização para participar de exportações. A integração em redes tem uma importância tão grande hoje que se pode atribuir às mesmas o pioneirismo na prática da qualidade integral que, diferentemente da qualidade total, pode ser perseguida não por uma firma isoladamente, mas por um grupo de empresas.

Onde se estabelecem estes consórcios - operando em rede e preocupados em manter baixo o custo transacional e em melhorar a qualidade integral - ocorre, segundo Amin (1993), o ideal de atmosfera industrial marshalliana, na qual elementos socioculturais concorrem para a redução de desperdícios, para a absorção de inovações tecnológicas, para o estabelecimento de novas relações com o consumidor, para a flexibilização, para a descentralização e para o ressurgimento da economia local.

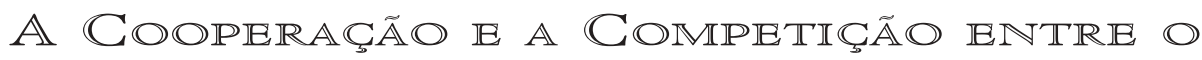 $\mathbb{E} \mathbb{M P R} \mathbb{R} S \mathbb{R} I A D O B A I A N O$}

Pesquisa $^{3}$ recente, e que teve como objeto o empresariado baiano, identificou vários elementos socioculturais que são reveladores de uma propensão a cooperar por parte dos agentes. A primeira delas é o modo pelo qual o empresário avalia sua empresa frente ao seu entorno. A imagem que este agente representa da própria empresa é uma medida importante do grau de auto-estima em relação aos próprios negócios e uma condição para iniciativas de cooperar. Uma elevada auto-estima se projeta na construção dos julgamentos feitos por terceiros. Supondo-se bem conceituado como empresário, e como empresa, o que se expressa, em princípio, por uma aceitabilidade de sua comunidade, o empresário não só poderá reagir bem às oportunidades para integrar organizações cooperantes, como tomar iniciativas ele mesmo de propô-las. Daí poder-se intuir que tanto melhor a auto-imagem maior é a propensão a cooperar.

A Tabela I, a seguir, mostra como esta variável foi tratada em referência a vários públicos. Junto à sua comunidade, como possível parceiro, a maioria dos empresários, 62,1\%, faz uma boa auto-representação, considerando que a sua imagem é ótima e boa. Como cliente, visto pelo ângulo dos fornecedores, esta marca se eleva, sendo que $92,0 \%$ dos investigados representam a auto-imagem como ótima e boa. Como fornecedor de bens e serviços junto à clientela, 90,4\%

\footnotetext{
${ }^{3}$ Baiardi \& Laniado, et alii: "Padrões Culturais e Desempenho na Sociedade Civil: Perfil e Atitudes do Empresariado Baiano", com apoio do CNPq.
} 
das respostas também se situam na faixa de ótima e boa. Surpreendentemente, por se tratar de uma atuação e de uma presença de certo modo recente, $88,3 \%$ das respostas dadas pelos empresários apontam para uma auto-imagem de ótima e boa no que concerne a atuação da empresa dentro de uma política de preservação e defesa do meio ambiente.

Tabela I

Imagem da Empresa

\begin{tabular}{l|c|c|c|c|c|c|c|c}
\hline Junto a diferentes públicos & \multicolumn{2}{|c|}{ Ótima } & \multicolumn{2}{c|}{ Boa } & \multicolumn{2}{c|}{ Regular } & \multicolumn{2}{|c}{ Total } \\
Como parceira de negócios & $\mathrm{N}$ & $\%$ & $\mathrm{~N}$ & $\%$ & $\mathrm{~N}$ & $\%$ & $\mathrm{~N}$ & $\%$ \\
Como cliente & 83 & 50,6 & 19 & 11,5 & 62 & 37,9 & 164 & 100 \\
Como provedora de bens & 84 & 56,0 & 54 & 36,0 & 12 & 8,0 & 150 & 100 \\
Com atuação ecologicamente & 42 & 28,5 & 91 & 61,9 & 14 & 9,6 & 147 & 100 \\
Correta & 53 & 36,0 & 77 & 52,3 & 17 & 11,7 & 147 & 100 \\
\hline
\end{tabular}

Fonte: Pesquisa de campo

Nota: total maior que o número de questionários devido à pergunta ser de múltipla escolha.

A propensão a cooperar também pode ser medida por um outro elemento sociocultural, observável ao nível da empresa. Trata-se da maior ou menor aceitação para estabelecer ligações e/ou associações com outras empresas. A Tabela II, abaixo, informa que $19 \%$ das empresas estudadas realizam algum tipo de ligação para efeito de negócios. Estas ligações se dão quase que de forma equivalente entre grupos nacionais e internacionais. Se for levado em conta que a maior parte das posições adotadas são de empresas de pequeno e médio porte - estimadas pelo número de funcionários e pelo capital social em cerca de $40 \%$ no estudo realizado e nas quais é menos freqüente realizar ligações/associações - pode-se concluir que a cooperação através de ligações ou associações entre empresas deste porte é um dado significativo.

\section{Tabela II}

\section{Ligações Econômicas das Empresas}

\begin{tabular}{l|c|c}
\hline Ligações ou associações com outros grupos empresariais & Freqüência Simples & $\%$ \\
\hline Não realiza & 124 & 81,0 \\
Realiza com grupo nacional & 13 & 8,5 \\
Realiza com grupo estrangeiro & 9 & 5,9 \\
Realiza sem informar o grupo & 7 & 4,6 \\
\hline Total & 153 & 100 \\
\hline
\end{tabular}

Fonte: Pesquisa de campo

Na mesma linha de análise, verificou-se que os empresários informam ao nível da auto-avaliação o desempenho das empresas em termos de competitividade, rentabilidade e engajamento em organizações e associações. $O$ exame individualizado de cada um destes fatores busca retratar o mundo real, a situação na qual as empresas, independentemente do julgamento que os empresários façam da importância da cooperação, praticam-na de fato, com determinação de fatores externos. Entre estes, ressaltam-se as solicitações de sindicatos patronais, de federações e de outras associações formais, condicionadas pela legislação ou por benefícios corporativistas. A análise em separado dos fatores que influenciam a cooperação parte do suposto de que a empresa se encontra situada em um sistema no qual os parâmetros se apoiam nos dois princípios cardinais da economia 
neoclássica, quais sejam o papel regulador de 'mão invisível' jogado pelo mercado e o modelo de concorrência. Neste suposto, a cooperação, ainda que presente, não é orgânica. Não se atribui à mesma nenhuma responsabilidade ou papel especial na obtenção de um outro nível de performance econômica. Por isso, do ponto de vista adotado neste trabalho, a análise só introduz, descritivamente, a questão. Para realçá-la analiticamente é realizado um cruzamento destes fatores.

A análise conjunta busca superar esses princípios neoclássicos e adotar a idéia de que a empresa tenta se organizar em um sistema reticular, no qual se trocam informações de modo horizontal, sem obstáculos nem filtros gerados por uma estrutura hierarquizada e convencional. Neste novo arranjo, produto de uma também nova cultura gerencial, dá-se como fundamental que toda a empresa tem, de um modo ou outro, a necessidade de estabelecer relações de colaboração sistemática com outras empresas, fundando uma rede com objetivos comuns. É neste caso que a competição perde espaço para a cooperação. A análise conjunta refere-se a uma situação tipo ideal, para a qual os agentes empresários podem estar capacitados.

O princípio cardinal da análise individualizada acima referida supõe que a eficiência do sistema econômico derive do confronto competitivo entre empresas. Seria o mercado promovendo a relação de competição entre as operadoras, cada uma delas movida pelo interesse próprio, impulsionadas a ter comportamentos considerados convenientes para toda a coletividade. A 'mão invisível' do mercado possibilitaria que o mecanismo de competição transformasse o impulso isolado como contribuição para o bem-estar coletivo (Benassi e Boari et alii, apud Buffa, 1994). O resultado da aceitação acrítica desta proposta tem impedido que se teorize sobre uma relação colaborativa mais recíproca e eficiente.

Do mesmo modo, para o segundo princípio cardinal, a aceitação acrítica do modelo de concorrência, presume-se que as empresas operadoras tenham um livre acesso à informação, negando que, em realidade, há um custo de troca de informações. De outro modo, presume-se que em um mercado sem imperfeições, plenamente concorrencial, as firmas estejam dotadas das informações necessárias para tomarem as decisões econômicas. O principal problema que a análise econômica tradicional acarreta é que se subestima o peso da informação nas trocas, porque se parte da premissa de que o mesmo esteja livremente disponível no mercado, o que não acontece.

A raiz deste pensamento reside na aceitação e no sucesso que teve a economia neoclássica e a teoria do equilíbrio. Este sucesso foi tão grande que nem mesmo as contestações da Escola de Cambridge e o keynesianismo foram suficientes para mudar este modo de pensar a economia. Até mesmo Schumpeter, que nada tinha de neoclássico, corroborou com esta simplificação ao estabelecer em seu esquema interpretativo a clara distinção entre invenção e inovação, sendo a primeira um produto do mundo científico e a segunda resultado da ação do agente inovador. Muito embora reconhecesse que sobre a inovação ocorreria o interesse de manutenção do segredo, a primeira, a invenção, a qual possibilitaria o desenvolvimento da segunda, seria de livre acesso. A forma como se organiza a ciência neste fim de século, inclusive nos arranjos que levam aos sistemas nacionais de inovação, mostra que informação em pesquisa, desenvolvimento e engenharia, $P \& D \& E$, não estão disponíveis para o conjunto de empresas. Estão tão somente para aquelas que buscam, através do financiamento à pesquisa, tornar imperfeitos, assimétrico, os mercados.

No mundo de hoje, o valor da informação, juntamente com o conhecimento técnico-científico, o domínio das técnicas de projetar, o domínio de saber fazer conforme certos objetivos (know how), além de impulsionar a produção e as vendas são determinantes no valor econômico da empresa, embora não figure nos seus balanços. São os chamados recursos não materiais, invisibles assetts. Atualmente eles têm um valor muito maior que a propriedade, stricto sensu, de maquinaria, edificações e mesmo de ativos bancários. Em algumas empresas modernas observa-se, inclusive, que o maior valor estratégico para garantir sua sobrevivência e expansão não é o hardware, mas sim o software.

Em vista destas considerações, pode-se dizer que, conforme a Tabela III, uma maioria significativa de empresários entrevistados considera suas empresas 
competitivas, tanto no âmbito regional, $88,3 \%$, quanto no âmbito nacional, $66,6 \%$. Somente $7,8 \%$ deles consideram-se pouco competitivos ao nível regional e $27,5 \%$ ao nível nacional. Estes dados têm um significado relevante, pois denotam um elevado grau de auto-estima e permeabilidade para iniciativas de reestruturação e de aquisição de tecnologias, iniciativas que sinalizam diretamente para uma propensão a cooperar. No entanto, é preciso considerar que a expressão de autoavaliação do grupo também carrega algo de crítico, pois transparece o convencimento de que não há necessidade de associar-se para compartilhar e obter informações estratégicas, que viabilizariam a competitividade.

\section{Tabela III}

\section{Competitividade das Empresas}

\begin{tabular}{l|c|c|c|c}
\hline \multirow{2}{*}{ Grau de Competitividade } & \multicolumn{2}{|c|}{ Regional } & \multicolumn{2}{c}{ Nacional } \\
\cline { 2 - 5 } & Freq. Simples & $\%$ & Freq. Simples & $\%$ \\
\hline Competitiva & 135 & 88,3 & 102 & 66,6 \\
Não competitiva & 12 & 7,8 & 42 & 27,5 \\
Não respondeu & 6 & 3,9 & 9 & 5,9 \\
\hline Total & 153 & 100 & 153 & 100 \\
\hline
\end{tabular}

Fonte: Pesquisa Campo

No que tange à rentabilidade, observa-se na Tabela IV que cerca de $70 \%$ das respostas admitem rentabilidade do negócio, o que também é uma dimensão positiva da auto-avaliação, revelando uma crença nas possibilidades da firma sobreviver e se expandir, inclusive pela via da cooperação. Menos de $30 \%$ das respostas admitiram a pouca rentabilidade, o que não configura, necessariamente, um quadro de perdas, de prejuízos.

Tabela IV

Rentabilidade da Empresa

\begin{tabular}{l|c|c|c}
\hline Grau de Rentabilidade & Freqüência Simples & $\%$ & Percentual Acumulado \\
\hline Muito rentável & 3 & 2,0 & 2,0 \\
Rentável & 62 & 40,5 & 42,5 \\
Regular & 41 & 26,8 & 69,3 \\
Pouco rentável & 43 & 28,1 & 96,4 \\
Não respondeu & 4 & 2,6 & 100 \\
\hline Total & 153 & 100,0 & \\
\hline
\end{tabular}

Fonte: Pesquisa de campo

O conjunto das tabelas analisadas informa indiretamente, como proxy, uma propensão afirmativa dos agentes entrevistados a participar de algum nível de organização multi-empresarial voltada para a cooperação. Os dados sobre o engajamento das empresas em organizações de vários tipos acrescentam um outro ângulo à análise, deslocando o entendimento da cooperação e da confiança do âmbito do econômico e do social na atuação da empresa para o foco do associativismo e do engajamento cívico, num sentido amplo e plural. A análise faz emergir de forma mais explícita a percepção dessa tendência, até agora indiretamente intuída.

Vale esclarecer que os níveis de engajamento do empresariado em organizações voltadas para enfrentar a desigualdade e as diversas formas de injustiça social no Brasil contemporâneo, não podem ser lidos, mecanicamente, como indicadores de valores cívicos afirmativos. Atualmente este nível varia muito a depender do acordo social dos grupos e classes e do papel que se reserva para o Estado na política 
de seguridade social e bem-estar. Na Escandinávia, por exemplo, não se questiona quanto os valores de fortalecimento da coesão e da redução da exclusão social estão generalizados no corpo social. No entanto, a participação do empresariado em organizações filantrópicas e de ajuda mútua é muito menor que no resto de Europa e nos Estados Unidos, devido ao papel hegemônico de intervenção, em todos os níveis, do Estado nos países nórdicos (Danish Cultural Institute, 1994).

A ressalva a fazer é que o não engajamento concreto de uma empresa em formas associativas com finalidades diversas não é unicamente a expressão de uma resistência a cooperar ou a não propensão para integrar organizações multi-empresariais. Em seu conceito de comunidade moral aplicado a corporações, French (1992) classifica os membros das mesmas em dois tipos: regulares e não regulares. Os integrantes do segundo tipo, uma categoria que não tem capacidade ou vontade de participar regularmente, são chamados de pacientes morais. Este conceito pode ser trazido para o presente objeto de estudo, permitindo que o empresariado baiano seja dividido em duas categorias: uma que acredita e participa da cooperação e outra que manifesta uma atitude passiva, embora não descreia ou tenha uma atitude contrária à cooperação.

Agregando uma análise de ordem mais sociológica, parece importante incorporar ao estudo destes agentes um grau de entendimento sobre o papel dos valores culturais e das tradições nas trocas sociais, entre elas os negócios, e a integração do agente econômico aos problemas mais gerais de suas comunidades. Pode-se dizer que a cooperação entre empresário, pessoa física, e comunidade depende também de como os sistemas de reciprocidade funcionam. Depende de se há ou não um forte grau de reciprocidade geral, aquela que disseminada na sociedade como um todo repercute em valores de cultura política e intensifica os laços entre indivíduos, não só nas relações horizontais (família e vizinhança), mas, também, nas relações verticais (classes, grupos de poder, organizações políticas) (Recchi, 1993; Laniado, 2000). Neste sentido, a cultura cívica no Brasil, um dos lados da cultura política, tem pouca densidade por causa do baixo grau de reciprocidade geral que existe no funcionamento dos sistemas, conforme as normas sociais. Historicamente, têm prevalecido condutas que expressam mais interesses individualizados ou agrupados a interesses coletivos por meio do clientelismo ou do corporativismo, o que enfraquece o sentido afirmativo que poderia estar agregado à conduta dos agentes. Logo, entender o grau de engajamento dos empresários é entender a questão por apenas um dos seus ângulos que, no entanto, é parte de uma tradição histórica mais ampla da sociedade como um todo, por si só mais complexa em termos da formação de um senso de cooperação cívica e de confiança nas instituições.

É à luz destas considerações que se avalia a visão dos empresários estudados sobre o seu próprio engajamento em organizações e os tipos de iniciativas envolvidas na caracterização da cooperação entre este grupo e a sociedade regional onde atua. Distribuído por onze categorias de engajamento, o desempenho cívico destes agentes é retratado como segue na Tabela V.

\section{Tabela V}

\section{Engajamento Associativo da Empresas}

\begin{tabular}{l|c|c|c|c|c|c|c|c}
\hline \multirow{2}{*}{$\begin{array}{l}\text { Engajamento em organizações } \\
\text { ou grupos sociais }\end{array}$} & \multicolumn{9}{|c|}{ Tipo de Engajamento } \\
\cline { 2 - 9 } & $\begin{array}{l}\text { Por Iniciativa } \\
\text { Própria }\end{array}$ & \multicolumn{2}{c}{$\begin{array}{c}\text { Por } \\
\text { Solicitação }\end{array}$} & \multicolumn{2}{c|}{$\begin{array}{c}\text { Não } \\
\text { Respondeu }\end{array}$} & \multicolumn{2}{c}{ Total } \\
\cline { 2 - 9 } & $\mathrm{N}$ & $\%$ & $\mathrm{~N}$ & $\%$ & $\mathrm{~N}$ & $\%$ & $\mathrm{~N}$ & $\%$ \\
\hline Sindicato patronal & 90 & 58,8 & 33 & 21,6 & 30 & 19,6 & 153 & 100 \\
Associação de classe & 88 & 57,5 & 25 & 16,3 & 40 & 26,1 & 153 & 100 \\
Grupo econômico em que atua & 44 & 28,8 & 14 & 9,2 & 95 & 62,1 & 153 & 100 \\
Associações culturais & 22 & 14,4 & 23 & 15,0 & 108 & 70,6 & 153 & 100 \\
Entidades educacionais & 25 & 16,3 & 20 & 13,1 & 108 & 70,6 & 153 & 100 \\
Associações esportivas & 10 & 6,5 & 23 & 15,0 & 120 & 78,4 & 153 & 100 \\
Associações filantrópicas & 29 & 19,0 & 24 & 15,7 & 100 & 65,4 & 153 & 100 \\
Associações de pesquisa & 17 & 11,1 & 18 & 11,8 & 118 & 77,1 & 153 & 100 \\
Entidades comunitárias & 19 & 12,4 & 22 & 14,4 & 12 & 73,2 & 153 & 100 \\
Entid. preserv. Meio ambiente & 30 & 19,6 & 16 & 10,5 & 107 & 69,9 & 153 & 100 \\
Outros & 1 & 0,7 & 0 & 0 & 152 & 99,3 & 153 & 100 \\
\hline
\end{tabular}

Fonte: Pesquisa de campo 
Como revelam os dados acima, a questão é complexa e multifacetada. Ademais, um empresário pode estar envolvido em mais de um tipo de associação, denotando preocupação com mais de uma questão social e ambiental na comunidade. Há uma incidência muito alta de adesão a organizações consideradas de classe e patronais, como sindicatos e federações, em cerca de $80 \%$. As mesmas respostas sinalizam também para um tipo de envolvimento movido por iniciativa própria, com cerca de $60 \%$, comparativamente ao envolvimento estimulado, que tem uma participação de apenas $20 \%$, tanto no caso de sindicatos como de federações.

No outro extremo, encontra-se o baixo envolvimento em organizações pouco atrativas para os empresários, aquelas com as quais eles têm mais dificuldade em se comprometer, como expresso pelo alto índice de respostas não preenchidas, para indicadores como os de pesquisa e P\&D (77,1\%) ou as de finalidade esportiva $(78,4 \%)$, indicando uma atitude de baixo padrão pró-ativo. Em uma posição intermediária, de média atratividade para o associativismo afirmativo, está a associação operacional ou produtiva (38\%), a filantrópica (34,7\%), a de proteção ao meio ambiente $(30,1 \%)$, a de apoio às comunidades situadas no entorno das empresas $(26,8 \%)$, a de apoio ao desenvolvimento cultural e de apoio à educação, com $29,4 \%$ cada.

Os dados mostram um certo grau de engajamento cívico, em níveis considerados razoáveis (Laniado \& Baiardi, 1998). Entretanto, os mesmos não permitem sugerir a existência de alguma relação entre o impulso associativista do empresariado baiano e os resultados em termos de competitividade e rentabilidade. De outro modo, seria desejável saber se a propensão a cooperar está mais presente e se existe alguma relação estabelecida entre a mesma com a competitividade e a rentabilidade. Alguns ensaios de análise nesta direção podem ser feitos combinando-se algumas das variáveis presentes nos dados apresentados acima. A análise das mesmas pode ser conduzida dentro de uma perspectiva diferente daquela que contempla a empresa como situada em um sistema de modelos analíticos neoclássicos e sugerir uma outra interpretação.

Toma-se como suposto que entre os empresários investigados há um redirecionamento para uma mudança cultural que exige uma fase de aprendizado e experimentação. Nesta nova condição, as empresas, progressivamente, vão descobrindo as vantagens de exercitar a cooperação sem abrir mão da competição, ou de buscar ser mais competitivas em comunidade ou grupo, integrando-se em consórcios, redes, etc. É uma abordagem que se refere mais a uma tendência voltada para uma situação ideal e para a qual, como já foi mencionado, os empresários assinalam um rumo de evolução. Isto é, o campo da ação social dos agentes se abriria para uma solidariedade mais abrangente, num sistema de trocas que intensificam formas de reciprocidade mais benéficas para os grupos envolvidos nas atividades econômicas, mas gerando, também, benefícios mais ampliados para a sociedade como um todo.

Conjeturar sobre a propensão à cooperação do empresariado baiano a partir desta abordagem implica em buscar estabelecer uma possível relação entre a tendência associativista, por um lado, e a competitividade e a rentabilidade, pelo outro. Na Itália, por exemplo, em vários distritos industriais este valor associativista levou a uma preferência pela integração horizontal, comparativamente à integração vertical. Isto significou a busca de um recorte mais preciso do esforço empreendedor, que, na prática, significava que cada empresa procurasse se especializar na atividade que melhor soubesse desempenhar. Concretamente, se expressou por uma opção pela cooperação vis a vis a competição pura e simples ou aquela que se dá dentro dos supostos do modelo de livre mercado: da maior eficiência alocativa operada pela "mão invisível", do melhor desempenho do sistema econômico como resultante do confronto competitivo entre as empresas e do modelo de concorrência, que assume como hipótese básica o livre acesso à informações, entendidas como inovações tecnológicas.

Nesta nova perspectiva, na qual a cooperação se impõe, os consórcios e as redes passam a se constituir mais facilmente. Os produtos ou bens finais resultan- 
tes das atividades produtivas tendem a compartir uma dimensão coletiva, no sentido de que, da sua produção, participem várias empresas. A conseqüência positiva desta iniciativa, na realidade italiana, foi que um grupo de pequenas e médias empresas passou a exprimir uma força competitiva análoga à de uma grande corporação, com a vantagem desse sistema organizado em rede ser mais flexível e mais reativo a mudanças necessárias.

Em outras palavras, a implantação de uma rede na qual cada empresa funciona como um nó de tomada de decisão suplantou, com vantagens, as estruturas hierárquicas e a integração vertical. O sistema tendeu a se organizar em linha, na qual as várias funções, como projeto, aquisição, produção, comercialização etc., podem ser desempenhadas por uma ou mais empresa. Conseqüentemente, não estão presentes no mesmo os diversos níveis de poder e responsabilidade como diretor geral, diretor de função, chefe de setor, chefe de departamento etc., que freqüentemente funcionam como entraves. As empresas que se integram em rede são consideradas empresas planas, não piramidais, subdividindo-se em poucos níveis hierárquicos, o que facilita a comunicação internamente e o envolvimento de todos os recursos humanos com eventuais problemas que venham a surgir (Benassi e Boari et alii, apud Buffa, 1994).

As redes de empresas não têm sempre o mesmo caráter. Adquirem formas variadas e podem, grosso modo, ser classificadas em três tipos: homeostática, adaptativa e morfogenética. A do primeiro tipo, homeostática, é a rede que se mantém em sintonia com um único objetivo dado. A adaptativa, ao contrário, pode estar em sintonia com dois ou mais objetivos. A morfogenética, por sua vez, é aquele tipo de rede que se reconstrói sempre que for necessário, entrando, dinamicamente, em sintonia com novos objetivos que surjam. Portanto, além de flexível, é antecipadora das adaptações que por ventura se tornem necessárias.

A organização em rede se dá predominantemente entre as pequenas e médias empresas, mas nada impede que se dê entre as grandes também. Do mesmo modo, a constituição de uma rede pode se dar internamente. Entre os exemplos mais bem sucedidos de constituição de redes estão o codesign e o simultaneus engineering que podem ser praticados por grandes e pequenas empresas (Benassi, apud Buffa, 1994; Boari et alii, apud Buffa, 1994).

Muito embora a pesquisa empírica que subsidia este estudo não tenha enfocado o aspecto das redes no desempenho empresarial, a ser estudado em outra oportunidade, os dados de que se dispõe permitem avaliar a questão em termos da propensão para a cooperação, condição básica para o envolvimento em redes a partir de resultados concretos em termos de rentabilidade e competitividade para empresas que pratiquem algum tipo de associação. Das várias modalidades de associação previstas neste estudo, e elencadas na tabela anterior, selecionaram-se algumas para serem correlacionadas com os fatores de competitividade e rentabilidade. São elas as associações em sindicatos e em federações da indústria, por significar a possibilidade de ações conjuntas e lobbies em defesa de uma categoria, e a associação para compartilhar investimentos em pesquisa, desenvolvimento e engenharia, P\&D\&E, por significar a possibilidade de absorver inovações tecnológicas.

Os resultados obtidos para a correlação entre tipo de associação e competitividade ao nível regional evidenciam, claramente, que há uma forte relação entre estar engajado em sindicatos e em federações e ser competitivo na região, com convergência de $83 \%$ e $76,3 \%$, respectivamente, conforme observado na Tabela VI. No entanto, o mesmo não se verifica no que concerne à participação em associações para financiamento da P\&D\&E. Neste caso, obteve-se uma convergência de apenas $22 \%$ das respostas para explicar a ligação entre competitividade e associação, mostrando ser fraco ainda o objetivo de compartiIhar o elevado custo de produção de inovações tecnológicas, ou mesmo de engajarse na produção, stricto sensu, de novas tecnologias. 
Tabela VI

Competitividade ao Nível Regional X Engajamento

\begin{tabular}{l|c|c|c|c}
\hline \multirow{2}{*}{ Tipos de engajamento } & \multicolumn{3}{|c}{ Competitividade ao nível regional } \\
\cline { 2 - 5 } & \multicolumn{2}{|c|}{ Sim } & $\mathrm{c}$ & $\%$ \\
\cline { 2 - 5 } & $\mathrm{N}$ & $\%$ & 9 & 75,0 \\
\hline Sindicato patronal & 112 & 83,0 & 9 & 75,0 \\
Federação/associação da classe & 103 & 76,3 & 5 & 41,7 \\
Grupos/associações de P\&D & 30 & 22,2 & 5 \\
\hline
\end{tabular}

Fonte: Pesquisa de campo

Remetendo a análise para uma abrangência maior, cruzando tipo de associação e competitividade ao nível nacional, as evidências são maiores. Há claros indícios de que o engajamento em sindicatos $(85,3 \%)$ e em federações $(83,3 \%)$ corrobora com a competitividade ao nível nacional, conforme Tabela VII. Quanto a se associar para financiar investimentos em P\&D\&E e ser competitivo ao nível nacional, há uma convergência bem menor, de $24,5 \%$ das respostas, mas, no entanto, sugerindo ligação discretamente maior comparativamente ao nível regional. Isto permite supor que parte da competitividade pode estar associada a este tipo de organização, cujo objetivo é compartilhar o elevado custo de produção de inovações tecnológicas.

Tabela VII

Competitividade ao Nível Nacional X Engajamento

\begin{tabular}{l|c|c|c|c}
\hline \multirow{2}{*}{ Tipos de engajamento } & \multicolumn{4}{|c}{ Competitividade ao nível nacional } \\
\cline { 2 - 5 } & \multicolumn{2}{|c}{ Sim } & \multicolumn{3}{c}{ Não } \\
\cline { 2 - 5 } & $\mathrm{N}$ & $\%$ & $\mathrm{~N}$ & $\%$ \\
\hline Sindicato patronal & 87 & 85,3 & 32 & 76,2 \\
Federação/associação da classe & 85 & 83,3 & 25 & 59,5 \\
Grupos/associações de P\&D & 25 & 24,5 & 9 & 21,4 \\
\hline
\end{tabular}

Fonte: Pesquisa de campo

A linha de conduta dos agentes na correlação entre os fatores estudados se mantém em relação à rentabilidade. Os dados da Tabela VIII indicam uma forte convergência de respostas, associando diferentes graus de desempenho positivo com a inserção em sindicatos patronais e federações de classe e uma baixa convergência de respostas associando a inserção em organizações de financiamento a P\&D\&E e a rentabilidade. Os que se filiam a sindicato patronal se consideraram rentáveis $(87,1 \%)$ e regulares $(78 \%)$ em alta proporção. Os que se filiam à federação/associação de classe também expressaram uma correlação positiva, de 77,4\% para rentável e 73,2\% para regular. No geral, pode-se dizer que, dificilmente, uma empresa desconectada com as organizações corporativistas sobreviveria. De outro modo, independente do nível de rentabilidade, esta se materializa de forma satisfatória entre as empresas que se associam aos sindicatos e federações. No que concerne à participação em entidades de apoio à $P \& D \& E$, observa-se uma baixa convergência de respostas interligando uma tendência associativista em direção à pesquisa e à rentabilidade.

Quanto ao resultado para P\&D\&E, há um considerável declínio comparativo na correlação estabelecida entre os fatores analisados, com um grau de correlação positiva de $25,8 \%$ para rentável e $19,5 \%$ para regular. 
Tabela VIII

Rentabilidade da Empresa X Tipos de Engajamento

\begin{tabular}{|c|c|c|c|c|c|c|}
\hline \multirow{3}{*}{$\begin{array}{c}\text { Rentabilidade da } \\
\text { empresa }\end{array}$} & \multicolumn{6}{|c|}{ Tipo de Engajamento } \\
\hline & \multicolumn{2}{|c|}{$\begin{array}{l}\text { Sindicato } \\
\text { Patronal }\end{array}$} & \multicolumn{2}{|c|}{$\begin{array}{c}\text { Federação e } \\
\text { Associação de classe }\end{array}$} & \multicolumn{2}{|c|}{$\begin{array}{c}\text { Grupo e } \\
\text { Associação em P\&D\&E }\end{array}$} \\
\hline & $\mathrm{N}$ & $\%$ & $\mathrm{~N}$ & $\%$ & $\mathrm{~N}$ & $\%$ \\
\hline Muito rentável & 1 & 33,3 & 1 & 33,3 & 0 & 0 \\
\hline Rentável & 54 & 87,1 & 48 & 77,4 & 16 & 25,8 \\
\hline Regular & 32 & 78,0 & 30 & 73,2 & 8 & 19,5 \\
\hline Pouco rentável & 35 & 81,4 & 34 & 79,1 & 11 & 25,6 \\
\hline
\end{tabular}

Fonte: Pesquisa de campo

\section{CONSIDERAÇÕES FINAIS}

Antes de qualquer julgamento mais definitivo sobre a propensão do empresariado baiano a assumir papéis modernizantes em termos econômicos como fruto da contemporaneidade, caberia fazer referência à sua plasticidade atual no moldar-se de acordo com as tendências, absolutamente paradoxal em relação à sua gênese. O empresário baiano como um agente econômico nasce na metade do século XIX e emerge de uma estratificação corporial ou estamental e não de uma sociedade de classes (Baiardi \& Laniado, 1999).

Esta diferença, de nada irrelevante, tem implicações no que tange à mentalidade. Pertencer a uma classe social significa pensar economicamente o processo produtivo, exercitar relações de classe no circuito da produção. Significa ser burguês e encarnar o ideal de acumulação pela paixão ao lucro, sendo este um instrumento de poder pessoal. Pertencer a um estamento ou corpo significa desconhecer ou recusar o risco no processo produtivo e ver a propriedade dos meios de produção como um direito natural, estando o poder pessoal assentado em uma existência milenar, emanado da Igreja católica quando do início da ordenação feudal.

Este corpo ou estamento, ou proto classe, não poderia ter valores, padrões culturais, que correspondessem aos dos empresários da Inglaterra, Alemanha e Países Baixos, quando da constituição do capitalismo europeu, conforme descrito por Moore (1999) e Landes (1994). Na Europa de então vigia um padrão comportamental baseado na ética, num conjunto de valores que regiam a vida cotidiana e que levavam a um ascetismo mundano, uma vida na qual o tempo e a energia do sujeito eram exclusivamente dedicados a atividades meritórias e à diligência, à parcimônia, à austeridade, o que não poderia levar senão à formação de capitais seminais. O que acontecia no Brasil e na Bahia era algo completamente diferente, a começar pelo entendimento do que deveria ser a relação capital-trabalho após a abolição da escravidão, o que exigiu do nascente operariado urbano uma longa batalha para obter direitos que já haviam se generalizado na Europa. Demais, como salienta Pedrão (1996), o primeiro impulso industrializante da Bahia, que transcorreu entre 1830 e 1895, baseado na produção têxtil, tinha como fonte de financiamento uma cadeia de negócios na qual entravam o tráfico de escravos e o contrabando.

Com gênese no capital comercial e no tráfico de escravos, atividades muito afins, vide Caldeira (1995), esta classe somente recebe impulsos modernizantes quando a Bahia começa a diversificar sua estrutura econômica a partir da segunda metade do século XX. Não obstante haja registros isolados de empresários com valores modernos - são citados os casos da Valença Industrial, Empório Industrial etc., que na segunda metade do século XIX constituíam um parque industrial têxtil considerável, o maior do Brasil, e no qual se constatavam condutas empresariais 
mais próximas de uma burguesia emergente - isto não era a regra (Gorender, 1986; Pedrão, 1996). De todos os modos, esses casos não eram suficientes para determinar valores modernos de modo mais generalizante, o que leva à pergunta, quando e como a Bahia engendrou uma classe empresarial moderna?

O mais provável é que se possa falar de transformações mais nítidas a partir de 1950 quando têm início, por força de intervenções públicas, as mudanças na infraestrutura e na estrutura produtiva, as quais repercutiram na mentalidade do empresariado baiano. Destarte, é possível propor a hipótese que a semente de um padrão moderno já houvesse a partir dos casos referidos e que a metade do século $X X$ é o ponto de inflexão para o início do predomínio de um outro padrão cultural que não se distingue, substancialmente, daquele de regiões mais industrializadas do Brasil.

Destarte, não causa espécie que os dados analisados sugiram um perfil do empresariado baiano que contempla uma propensão a valorizar relações de competição e relações de cooperação. Demais, autorizam também pensar que este agente admite a possibilidade de simultaneidade da cooperação e da competição. Conquanto as interpretações não sejam fortemente alvissareiras, não o são, por outro lado, desanimadoras. Os valores do empresário baiano, no que concerne a uma perspectiva de atuação sistêmica que contemple momentos de cooperação e momentos de competição, são afirmativos, muito embora a esse posicionamento não corresponda necessariamente uma praxis generalizada. É o que permite supor que a cooperação, nos marcos de estruturas inter e supra firmas, não encontraria resistência da parte deste empresariado para renovar-se. Alguns resultados positivos em termos de rentabilidade e competitividade podem, de certa forma, ser percebidos como decorrentes de uma atitude pró-associativismo, abrindo o campo da ação empresarial para uma perspectiva de organização em rede, minimamente significativa. A propensão a cooperar pode, portanto, ser assumida em relação ao empresariado baiano, em que pese esta prática não esteja ainda solidamente disseminada e dependa também de fatores de mudança cultural em relação a formas de trocas mais recíprocas e de uma percepção de bem comum mais ampliada.

\section{REFERENCIAS BIBLIOGRÁFICAS}

AMIN, A. Distretti industriali in un contexto globale che cambia: Santa Croce sull'Arno. In: LEONARDI, R. e NANETTI, R. (org.) Lo sviluppo regionale nell'economia europea integrale. Venezia, Marsilio Editori, 1993.

BAIARDI, A. \& LANIADO, R. N. "A construção de categorias de análise no estudo da temática empresarial". Organizações e Sociedade, Vol.6, no 15, maio/ago. 1999

Padrões culturais e desempenho na sociedade civil: perfil e atitudes do empresariado baiano. Salvador: NPGA/UFBA, relatório final de pesquisa, encaminhado ao CNPq em setembro de 1999.

BUFFA, C. Oltre l'operaio oltre il robot. Turino: FIAT Comunicazione ed Immagine (2000 giorni al 2000), 1994

CALDEIRA, J. Mauá, empresário do Império. São Paulo: Companhia das Letras, 1995.

CIANFERONI, R. Radici, imaginario e condizioni dello svilupo integrale di qualità della Toscana. In: LEONARDI, R. e NANETTI, R. (org) Lo sviluppo regionale nell'economia europea integrale. Venezia, Marsilio Editori, 1993.

COUTINHO, L. \& FERRAZ, J.C. (orgs.) Estudo da competitividade da indústria brasileira. São Paulo: Papirus/Editora Unicamp, 1994.

DANISH CULTURAL INSTITUTE, The welfare society in transition: problems and prospects of the welfare model. Copenhagen: Danish Cultural Institute, 1994

FARINA, E.M.Q. e ZYLBERSTAJN, D. Competitividade e organização das cadeias agroindustriais. São Paulo: PENSA, 199..

FRENCH, P. A et alii. Corporations in the moral community. Forth Worth: Harcourt Brace Jovanovich College Publishers, 1992. 
GORENDER, J. A burguesia brasileira. São Paulo: Brasiliense, 1986.

LANDES, D.S. O prometeu desacorrentado: transformação tecnológica e desenvolvimento industrial na Europa ocidental, desde 1750 até a nossa época. Rio de Janeiro: Nova Fronteira, 1994.

LANIADO, R. N. "Institutional performance and justice in relation to social exclusion in contemporary Brazil". In: VIIIth Biennial Conference of the International Society for Justice Research. Rishon LeZion, Israel, September 2000.

LANIADO, R. N. e BAIARDI, A. Padrões culturais e desempenho empresarial numa economia em mudança: o caso da Região Metropolitana de Salvador, Organizações e Sociedade, V. 5, n. 11, jan/abr. 1998.

MOORE, B. Aspectos morais do crescimento econômico. Rio de Janeiro: Editora Record, 1999.

NORTH, D. Institutions, institutional change and economic performance. Cambridge: Cambridge University Press, 1990.

Winter 1991. Institutions. Journal of Economic Perspectives, Volume 5, Number 1Economic performance through time. Washington: Washington University St. Louis, 1993.

PEDRÃO, F.C. O Recôncavo Baiano na origem da indústria de transformação no Brasil. In: SZMRECSÁNYI, T. et alii (orgs) História econômica da independência e do Império. São Paulo: Editora HUCITEC, 1996.

PIORE, M. J. e SABEL, C.F. Italian small business development: lessons for U.S. and Ustrial policy, in American business. In: International competition: government policies and corporate strategies. Ithaca: Cornell University Press,1983.

PUTMAN, R. La tradizione civica nelle regione italiane (do inglês: Making democracy work), Milano, Arnoldo Mondadori Editore, 1994.

RECCHI, E. - "Reciprocità. Un nome per tre concettti". In: Stato e Mercato, n039, December, 1993

WILLIAMSON, O. E. The economic institutions of capitalism: firms, markets, relational contracting, New York: The Free Press, 1985.

Comparative economic organizations: the analysis of discrete structural alternatives. Administrative Science Quartely, 36, pp. 269-296, 1991. Transaction cost economics and organiztion theory. Industrial and Corporate Change, V. 2, n. 2, pp107-156, 1993. 